\title{
Photoperiodic Responses of the Squash Bug (Heteroptera: Coreidae): Diapause Induction and Maintenance
}

\author{
JAMES R. NECHOLS \\ Department of Entomology, Kansas State University, \\ Manhattan, Kansas 66506
}

\begin{abstract}
Environ. Entomol. 17(3): 427-431 (1988)
ABSTRACT The squash bug, Anasa tristis DeGeer, undergoes a reproductive diapause from late summer to spring in northeastern Kansas. In the laboratory, diapause was induced in $100 \%$ of adult females reared under photoperiods shorter than 14:10 (L:D) and in a variably lower percentage of the population under all longer photoperiods. The critical photoperiod for diapause induction falls between 14:10 and 14.5:9.5; this range compares closely with prevailing natural daylengths when $50 \%$ of the adult population enters diapause in the field. Between October and March, short daylengths maintained, and long daylengths terminated, diapause in field-sampled adults. Under natural daylength at $26^{\circ} \mathrm{C}$, the duration of diapause became progressively shorter with advancing sample date. In nature, the photoperiodic maintenance of diapause is completed in most of the population by late May. A prolonged diapause probably serves to prevent premature postdiapause development during the thermally variable spring conditions encountered in Kansas. Some implications of these findings for biological control and pest management programs are discussed.
\end{abstract}

KEY WORDS Insecta, Anasa tristis, photoperiod, diapause

The SQlash bug (SB), Anasa tristis DeGeer, is an important pest of cucurbitaceous crops throughout much of North America. Despite its broad distribution and relative importance, few studies have been made of this pest's biology (but see Worthley 1923, Elliot 1935, Beard 1940, Nechols 1987). Particularly lacking are experimental investigations of the factors that control the seasonal cycle. Such phenological studies provide the basis for understanding the seasonal synchrony of pests with natural enemies, host plants, and agronomic practices. Thus, this information is necessary for developing integrated or biological control programs for the SB.

Diapause is the primary means by which temperate zone insects and related arthropods synchronize their seasonal cycles with the availability of essential resources (see Tauber \& Tauber 1976 , Tauber et al. 1986) and with the occurrence of favorable physical conditions (see Tauber et al. 1985). Because photoperiod is the dominant environmental factor used by insects to regulate diapause (Tauber \& Tauber 1973, 1976; Beck 1980; Tauber et al. 1986), I examined the influence of this factor on various aspects of SB dormancy. Specifically, I determined the critical photoperiod for diapause induction in the laboratory, provided evidence for photoperiodic maintenance of diapause throughout dormancy, and established when the photoperiodic regulation of diapause terminates naturally in the field.

\section{Materials and Methods}

\section{Diapause Induction}

All experimental animals were the $F_{1}$ progeny of field-collected, overwintered adults. Ovipositing stock adults were maintained on potted 'Green Zucchini' and 'Early Prolific Straightneck' squash (Cucurbita pepo L.; Harris Seed, Rochester, N.Y.) at $27 \pm 1^{\circ} \mathrm{C}$ and a photoperiod at 16:8 (L:D).

Within $24 \mathrm{~h}$ of oviposition, egg masses were transferred to one of the experimental photoperiods $\left(27 \pm 1^{\circ} \mathrm{C}\right.$ ) (see Table 1 ). On the day of hatch, first-instar nymphs were moved into frame cages that contained potted straightneck squash plants. Plants were changed as needed and bugs were reared to the adult stage under their respective photoperiodic conditions.

The day after emergence, adult SB were transferred to individual squash plants inside cylinder cages. Each cage contained one to three pairs of adults (female and male). Daily, each cage in every condition was examined and plants were changed as needed. Dates of mating and oviposition were recorded. On day 10, SB females were dissected in a $3 \%$ solution of $\mathrm{NaCl}$ and examined for ovarial development; the degree of ovarial development was noted. Females that lacked mature or developing oocytes and showed no expansion of ovarioles were considered to be in, or entering, diapause.

The percentage of females in diapause was com- 
puted for each photoperiod, and the critical photoperiod was derived by standard procedures.

\section{Diapause Maintenance and Termination}

Field Collection and Storage. Large numbers of SB adults were collected in early September 1984 from a pumpkin field located 2 mi south of Manhattan, Kans. These were transferred to screencovered cages that were sunk into the ground. Each cage contained insulation material (scrap wood and styrofoam sheets); a fresh pumpkin was provided until early October as a source of food and water.

Experimental Procedure. Natural populations of the SB enter a reproductive diapause by early September (see Nechols 1987). To examine the photoperiodic influence on diapause maintenance, I sampled the SB monthly from October to May (except in April) and subjected them to several photoperiodic conditions, including natural daylength.

On each sample date, 5 to 12 pairs (female and male) of adult bugs were confined together in frame cages on potted zucchini plants (cv. Zucchini Elite) with access to moistened cotton wads as a source of free water. The cages were then placed in growth chambers under constant short or long daylength $\left(27 \pm 1^{\circ} \mathrm{C}\right)$, or under natural daylength in a room that was maintained at $26 \pm 2^{\circ} \mathrm{C}$ (Table 2).

Plants were changed weekly or when signs of wilting or yellowing appeared. Detailed inspections were made twice a week until reproductive activity (mating or oviposition) was noticed, and then daily thereafter. Mating pairs were isolated in plastic cylinder cages over individual zucchini plants. When egg masses were found in the group cage, each female was isolated with a male and these pairs also were placed in individual cylinder cages. If there were fewer males than females, males were rotated among the females every other day.

On each inspection date, the number and sex of dead bugs were recorded. Fertility was established by holding egg masses in shell vials until hatch. Estimates of diapause duration included the postdiapause reproductive developmental period and were computed as the number of days between the date of collection in the field and the date of first oviposition. Mating was not used as an indicator of diapause termination because it was not possible to make observations frequently enough to determine all matings that occurred. Also, some females that copulated appeared to remain in diapause.

Differences in time to oviposition under long and short daylength conditions were considered as evidence for a photoperiodic maintenance of diapause. Conversely, the photoperiodic maintenance of diapause was considered terminated when uniform oviposition times were observed under all conditions. The Wilcoxon two-sample test was used to analyze for differences in preoviposition periods among photoperiods (Sokal \& Rohlf 1981).
Table 1. The percentage of $A$. tristis females in reproductive diapause $10 \mathrm{~d}$ after emergence when reared in the laboratory under the indicated photoperiods at $27 \pm 1^{\circ} \mathrm{C}$

\begin{tabular}{lccc}
\hline \hline Photoperiod (L:D) & $\begin{array}{c}\text { No. adults } \\
\text { tested }\end{array}$ & $\begin{array}{c}\text { No. in } \\
\text { diapause }\end{array}$ & $\%$ diapause \\
\hline $13: 11$ & 16 & 16 & 100 \\
$13.5: 10.5$ & 15 & 15 & 100 \\
$14: 10$ & 14 & 13 & 92.9 \\
$14.5: 9.5$ & 17 & 2 & 11.8 \\
$15: 9$ & 43 & 5 & 11.6 \\
$15.5: 8.5$ & 16 & 2 & 12.5 \\
\hline
\end{tabular}

\section{Results}

Diapause Induction. Between photoperiods of 14:10 and 14.5:9.5, there was a large decrease in the percentage of SB females entering diapause (93 to $12 \%$, respectively) (Table 1). All females entered diapause under photoperiods shorter than 14:10. On the other hand, under photoperiods of 14.5:9.5 or longer, a high percentage of the females avoided diapause and reproduced. A relatively low percentage of the females that were maintained under long days did not develop ovaries, and these appeared to be in diapause regardless of photoperiod (Table 1).

Diapause Maintenance and Termination. Under laboratory conditions, short days (11:13 photoperiod) maintained, and long days (16:8 photoperiod) terminated, diapause in SB females that were sampled from the field between October and March (Table 2). Under long daylength (16:8 photoperiod), the median number of days to oviposition was uniformly short ( 18 to $24 \mathrm{~d}$ ) in all samples. In contrast, the times to oviposition under short days were very long, ranging from $190 \mathrm{~d}$ in October to $158 \mathrm{~d}$ in December. These values were significantly (Wilcoxon two-sample test, $P<0.05$ ) longer than those under long days (Table 2). In all samples after December, most of the individuals died before terminating diapause.

In February, SB adults that were transferred to a 14:10 photoperiod terminated diapause and oviposited as quickly as under a 16:8 photoperiod, whereas under a 13:11 photoperiod, diapause was maintained for a long time (112 d) (Table 2). Under natural daylengths, there was a progressive decline in the duration of diapause with advancing sample date. The median time to oviposition ranged from $165 \mathrm{~d}$ in October to $60 \mathrm{~d}$ in March (Table 2).

The photoperiodic maintenance of diapause had ended in most of the population by the May sample date; only in this sample were the preoviposition periods similar under constant long and short daylengths and under the natural daylength condition (Table 2).

The percentage of adult SB mortality varied among sample dates and between sexes, but it was consistently higher in both sexes under short days than under long days (Table 3 ). With the exception of the February sample, mortality also was high 
Table 2. Median number of days for $A$. tristis females to oviposit after transfer from the field to various laboratory photoperiods on the indicated dates

\begin{tabular}{|c|c|c|c|c|c|c|c|}
\hline \multirow{2}{*}{$\begin{array}{l}\text { Photoperiod } \\
\text { (I.:I) }\end{array}$} & \multicolumn{7}{|c|}{ Sample dates (1984-85) } \\
\hline & 22 Oct. & 21 Nov. & $22 \mathrm{Dec}$ & $22 \mathrm{Jan}$. & 23 Feb. & 22 Mar. & 21 May \\
\hline $11: 13$ & $\begin{array}{c}190 \mathrm{a} \\
{[131-220]} \\
(4 / 9)\end{array}$ & $\begin{array}{c}162 a \\
{[154-165]} \\
(4 / 9)\end{array}$ & $\begin{array}{c}158 \mathrm{a} \\
{[127-187]} \\
(3 / 9)\end{array}$ & $\overline{-}$ & $\frac{181}{(1 / 12)}$ & $\overline{-}$ & $\begin{array}{l}10 \mathrm{~b} \\
{[5-13]} \\
(6 / 6)\end{array}$ \\
\hline $13: 11$ & - & - & - & - & $\frac{112}{(1 / 12)}$ & - & - \\
\hline $14: 10$ & - & - & - & - & $\begin{array}{r}17.5 b \\
{[11-20]} \\
(4 / 12)\end{array}$ & - & - \\
\hline $16: 8$ & $\begin{array}{c}19 \mathrm{~b} \\
{[19-33]} \\
(7 / 9)\end{array}$ & $\begin{array}{c}20 \mathrm{~b} \\
{[15-55]} \\
(7 / 9)\end{array}$ & $\begin{array}{c}22 b \\
{[17-31]} \\
(10 / 10)\end{array}$ & $\begin{array}{c}19 \\
{[16-26]} \\
(7 / 9)\end{array}$ & $\begin{array}{c}17 \mathbf{b} \\
{[12-19]} \\
(3 / 12)\end{array}$ & $\begin{array}{c}24 b \\
{[20-27]} \\
(5 / 7)\end{array}$ & $\begin{array}{c}7 b \\
{[6-10]} \\
(5 / 5)\end{array}$ \\
\hline Natural & $\begin{array}{c}165 a \\
{[130-182]} \\
(5 / 9)\end{array}$ & $\begin{array}{c}119 a \\
{[92-171]} \\
(5 / 9)\end{array}$ & $\begin{array}{c}127 \mathrm{a} \\
{[100-138]} \\
(4 / 9)\end{array}$ & $\begin{array}{c}100 \\
{[92-108]} \\
(2-10)\end{array}$ & $\begin{array}{c}79 \mathrm{a} \\
{[66-89]} \\
(11 / 12)\end{array}$ & $\begin{array}{c}61 \mathrm{a} \\
{[58-76]} \\
(4 / 8)\end{array}$ & $\begin{array}{l}10 \mathrm{~b} \\
{[8-34]} \\
(5 / 5)\end{array}$ \\
\hline
\end{tabular}

Medians within columns followed by a different letter are significantly different at the 5\% level (Wilcoxon two-sample test). [N-N] range of values; $(\mathrm{N} / \mathrm{N}$ ), number of ovipositing females/the total number of females per condition. Temperatures: constant photoperiods, $27 \pm 1^{\circ} \mathrm{C}$; natural daylength, $26 \pm 2^{\circ} \mathrm{C}$.

under natural daylengths; these rates were generally similar to those observed under short days (Table 3). Most female mortality in these cases occurred after a relatively long period in the laboratory. By contrast, when mortality did occur under long-day conditions, it nearly always did so within 1-2 wk of collection (Table 3 ). Under all photoperiods, adult mortality was lowest in the May sample.

\section{Discussion}

Diapause Induction. The critical photoperiod for diapause induction in adult female SB falls between photoperiods $14: 10$ and $14.5: 9.5$ at $27^{\circ} \mathrm{C}$. Although an insect's photoperiodic responses under laboratory conditions may differ from those in nature (see Tauber et al. 1986), it is noteworthy that this laboratory-derived critical photoperiod is very close to the natural daylengths (including civil twilight) experienced by SB adults in the field in northern Kansas during late August. At that time, $50 \%$ of the emerging females enter reproductive diapause (Nechols 1987). Thus, although the specific SB stages that respond to diapause-inducing conditions are not known, the combined field and laboratory data suggest that the adult (and possibly late nymphal) stages are sensitive.

The adult is the most sensitive stage in many other insects that undergo reproductive diapause (e.g., de Wilde 1954, Hodek \& Cerkasov 1961, Tauber \& Tauber 1970; for review, see also Tauber et al. 1986). It is also a sensitive stage in another coreid, the bean bug (Riptortus clavatus Thunberg) (Numata \& Hidaka 1982, 1983).

A low percentage of the females that were maintained under long days (i.e., 14.5 h or more of light) did not oviposit within $10 \mathrm{~d}$ of emergence under $27^{\circ} \mathrm{C}$ (Table 1). Dissections revealed ovaries with no signs of oogenesis. The condition of the fat body was variable but, in general, it was not well developed; thus, these individuals appeared to be in diapause. Beard (1940) reported a postdiapause preoviposition period of $1-2 \mathrm{wk}$ for an overwintered field population of the SB in Connecticut. However, no published data are available on the preoviposition period of nondiapause SB. In our cultures, SB females usually oviposit within 7-10 $\mathrm{d}$ of emergence under temperatures comparable with those used in the experiment. Thus, the complete absence of oocyte development in some females was probably not related to premature dissection times.

The observed variation in the incidence of diapause under long days implies that intraspecific genetic variability exists in the SB's response to diapause-inducing stimuli. This variability may be directly related to the photoperiodic response or to factors that modify this response (e.g., food quality, humidity, etc.). It is not clear whether this variability is expressed under field conditions.

Diapause Maintenance and Termination. The findings (Table 2) indicate that the $\mathrm{SB}$ remains sensitive to photoperiod throughout diapause. Thus, although the specific mechanisms and responses underlying diapause cannot be elucidated from the present data, short daylengths appear to play an important role in maintaining diapause. These results are supported by the mortality data (Table 3), which show that SB females that died before ovipositing lived for much longer periods under short daylengths than under long daylengths.

The percentage of female SB mortality was variable, but generally was much higher under shortday conditions (i.e., 11:13 photoperiod and natural daylengths) than under long days (Table 3). This 
Table 3. Percentage of adult SB mortality and median number of days to female death under various laboratory photoperiods $\left(27 \pm 1^{\circ} \mathrm{C}\right)$ for the indicated sample dates

\begin{tabular}{|c|c|c|c|c|c|c|c|c|}
\hline \multirow{2}{*}{$\begin{array}{l}\text { Photoperiod } \\
\text { (L:D) }\end{array}$} & \multirow{2}{*}{ Sex } & \multicolumn{7}{|c|}{ Sample dates (I984-85) } \\
\hline & & 22 Oct. & 21 Nov. & 22 Dec. & 22 Jan. & $23 \mathrm{Feb}$ & 22 Mar. & 21 May \\
\hline & & \multicolumn{7}{|c|}{ \% mortality ${ }^{a}$} \\
\hline $16: 8$ & $\begin{array}{l}q \\
\delta \\
\text { Total }\end{array}$ & $\begin{array}{ll}0 & (0 / 8) \\
0 & (0 / 7) \\
0 & (0 / 15)\end{array}$ & $\begin{array}{cc}22 & (2 / 9) \\
0 & (0 / 7) \\
12.5 & (2 / 16)\end{array}$ & $\begin{aligned} 0 & (0 / 9) \\
40 & (2 / 5) \\
14 & (2 / 14)\end{aligned}$ & $\begin{array}{ll}0 & (0 / 8) \\
0 & (0 / 3) \\
0 & (0 / 11)\end{array}$ & $\begin{array}{lr}73 & (8 / 11) \\
58 & (7 / 12) \\
65 & (15 / 23)\end{array}$ & $\begin{array}{ll}14 & (1 / 7) \\
71 & (5 / 7) \\
43 & (6 / 14)\end{array}$ & $\begin{array}{ll}0 & (0 / 5) \\
0 & (0 / 9) \\
0 & (0 / 14)\end{array}$ \\
\hline $11: 13$ & $\begin{array}{l}q \\
\delta \\
\text { Total }\end{array}$ & $\begin{array}{ll}37.5 & (3 / 8) \\
50 & (3 / 6) \\
43 & (6 / 14)\end{array}$ & $\begin{array}{ll}37.5 & (3 / 8) \\
71 & (5 / 7) \\
53 & (8 / 15)\end{array}$ & $\begin{array}{ll}62.5 & (5 / 8) \\
50 & (3 / 6) \\
57 & (8 / 14)\end{array}$ & $\begin{aligned} 100(7 / 7) \\
50(4 / 8) \\
73(11 / 15)\end{aligned}$ & $\begin{array}{lr}75 & (9 / 12) \\
90 & (9 / 10) \\
82 & (18 / 22)\end{array}$ & $\begin{array}{l}86(6 / 7) \\
86(6 / 7) \\
86(12 / 14)\end{array}$ & $\begin{array}{cc}0 & (0 / 16) \\
17 & (1 / 6) \\
4.5 & (1 / 22)\end{array}$ \\
\hline Natural & $\begin{array}{l}q \\
\vdots \\
\text { Total }\end{array}$ & $\begin{array}{l}37.5(3 / 8) \\
12.5(1 / 8) \\
25 \quad(4 / 16)\end{array}$ & $\begin{aligned} 44 & (4 / 9) \\
0 & (0 / 7) \\
25 & (4 / 16)\end{aligned}$ & $\begin{array}{ll}62.5 & (5 / 8) \\
25 & (2 / 8) \\
44 & (7 / 16)\end{array}$ & $\begin{aligned} 67 & (4 / 6) \\
0 & (0 / 6) \\
33 & (4 / 12)\end{aligned}$ & $\begin{array}{ll}17 & (2 / 12) \\
58 & (7 / 12) \\
37.5 & (9 / 24)\end{array}$ & $\begin{array}{l}50(4 / 8) \\
86(6 / 7) \\
67(10 / 15)\end{array}$ & $\begin{aligned} 17 & (1 / 6) \\
0 & (0 / 8) \\
7 & (1 / 14)\end{aligned}$ \\
\hline \multicolumn{9}{|c|}{ No. d to female death $b$} \\
\hline $16: 8$ & & - & $\begin{array}{l}15[2] \\
(7-32)\end{array}$ & - & - & $\begin{array}{c}6[8] \\
(3-33)\end{array}$ & $\begin{array}{c}57[1] \\
-\end{array}$ & - \\
\hline $11: 13$ & & $\begin{array}{c}124[3] \\
(124-157)\end{array}$ & $\begin{array}{c}21[3] \\
(18-94)\end{array}$ & $\begin{array}{c}69[5] \\
(19-126)\end{array}$ & $\begin{array}{l}120[7] \\
(17-198)\end{array}$ & $\begin{array}{c}8[9] \\
(6-121)\end{array}$ & $\begin{array}{l}35[6] \\
(6-84)\end{array}$ & 一 \\
\hline Natural & & $\begin{array}{c}140[3] \\
(122-140)\end{array}$ & $\begin{array}{l}145[4] \\
(82-181)\end{array}$ & $\begin{array}{l}121[5] \\
(5-138)\end{array}$ & $\begin{array}{c}43[4] \\
(20-83)\end{array}$ & $\begin{array}{l}37[2] \\
(6-67)\end{array}$ & $\begin{array}{l}14[4] \\
(6-39)\end{array}$ & $13[1]$ \\
\hline
\end{tabular}

${ }^{a}$ Numbers in parentheses denote the number dying/total number

${ }^{b}$ Numbers in parentheses denote the range of values; numbers in brackets are the number of females.

mortality may be related, in part, to the depletion of metabolic reserves during the SB's prolonged diapause under the warm experimental conditions $\left(27^{\circ} \mathrm{C}\right)$. Short daylengths probably had a direct influence on the very slow rate of diapause development. They also may have had an indirect effect by maintaining a low thermal threshold for diapause development (see Tauber \& Tauber 1976, Beck 1980). The high mortality in the February sample under both long and short daylengths is unexplained but, apparently, is related to at least one factor in addition to diapause duration (cf. Tables 2 and 3). The very low mortality observed under all conditions in the May sample is most likely associated with the short preovipositional periods of nondiapausing adults (Table 2).

The progressive decline in preoviposition times under natural daylengths indicates that the intensity of diapause diminishes gradually in the SB throughout autumn and winter (Table 2). Because the duration of diapause in this insect extends well beyond the winter solstice, it is possible that longor increasing-daylengths play an active role in terminating diapause by accelerating the rate of diapause development. In contrast, diapause in the bean bug ( $R$. clavatus) ends during the winter, and long days are apparently not important for its termination (Numata \& Hidaka 1984).

The results (Table 2) show that reproductive diapause in the SB persisted through late March, but that its photoperiodic regulation had terminated in most of the population by late May when responses to long, short, and natural daylengths were similar. Thus, unlike many temperate zone insects that end diapause by late autumn or early winter (see Tauber et al. 1986), this species remains in diapause throughout the winter and early spring. Because temperature conditions are highly variable in Kansas during late winter and early spring (National Oceanic and Atmospheric Administration 1985), a long diapause in the SB probably serves an adaptive function by preventing untimely postdiapause development. For example, natural host plants are not available until late May in Kansas (Barkley 1983), and temperature-sensitive cultivated hosts are not planted until after the frost-free date in early May.

This finding is relevant to the development and implementation of a biological control program for the $\mathrm{SB}$, because it can contribute to an understanding of parasitoid-host synchrony (see Tauber et al. 1983). A knowledge of SB phenology also has useful implications for IPM (e.g., for developing reliable temperature-dependent predictive models [see Tauber et al. 1986]).

\section{Acknowledgment}

I thank J. L. Tracy, C. Armendariz, and W. C. Albrecht (Kansas State University) for technical assistance. I appreciate the helpful suggestions made by $\mathrm{M}$. J. Tauber and C. A. Tauber (Comell University) and two anonymous reviewers on earlier drafts of this paper. This research was supported by Kansas Agricultural Experiment Station Hatch Project 546. This is Contribution No. 87-293-J from the Kansas Agricultural Experiment Station.

\section{References Cited}

Barkley, T. M. 1983. Field guide to the common weeds of Kansas. University of Kansas, Lawrence, Kans.

Beard, R. L. 1940. The biology of Anasa tristis DeGeer, with particular reference to the tachinid 
parasite, Trichopoda pennipes Fabr., pp. 597-679 In Connecticut Agricultural Experiment Station Bulletin 440.

Beck, S. D. 1980. Insect photoperiodism, 2nd ed. Academic, New York.

de Wilde, J. 1954. Aspects of adult diapause in insects, with special reference to the Colorado potato beetle Leptinotarsa decemlineata Say. Arch. Neerl. Zool 10: $375-378$.

Elliot, D. C. 1935. The squash bug in Connecticut, pp. 224-231. In Connecticut Agricultural Experiment Station Bulletin 368 .

Hodek, I. \& J. Cerkasov. 1961. Experimental influencing of the imaginal diapause in Coccinella septempunctata L. (Coccinellidae, Col.). Acta Soc. Zool. Bohem. 25: 70-90.

National Oceanic and Atmospheric Administration. 1985. Record of river and climatological observations. U.S. Department of Commerce, Manhattan, Kans.

Nechols, J. R. 1987. Voltinism, seasonal reproduction and diapause in the squash bug (Heteroptera: $\mathrm{Co}$ reidae) in Kansas. Environ. Entomol. 16: 269-273.

Numata, H. \& T. Hidaka, 1982. Photoperiodic control of adult diapause in the bean bug, Riptortus clavatus Thunberg (Heteroptera: Coreidae). I. Reversible induction and termination of diapause. Appl. Entomol. Zool. 17: 530-538.

1983. Photoperiodic control of adult diapause in the bean bug, Riptortus clavatus Thunberg (Heteroptera: Coreidae). II. Termination of diapause induced under different photoperiods. Appl. Entomol. Zool. 18: 439441.

1984. Photoperiodic control of adult diapause in the bean bug, Riptortus clavatus Thunberg (Heteroptera Coreidae). IV. Food and post-diapause development. Appl. Entomol. Zool. 19: 443-447.

Sokal, R. R. \& F. J. Rohlf. 1981. Biometry, 2nd ed. Freeman, San Francisco.

Tauber, M. J. \& C. A. Tauber. 1970. Adult diapause in Chrysopa carnea: stages sensitive to photoperiodic induction. J. Insect Physiol. 16: 2075-2080.

1973. Insect phenology: criteria for analyzing dormancy and for forecasting postdiapause development and reproduction in the field. Search (Agriculture) Cornell University Agricultural Experiment Station, Ithaca, New York, vol. 3.

1976. Insect seasonality: diapause maintenance, termination, and postdiapause development. Annu. Rev. Entomol. 21: 81-107.

Tauber, M. J., C. A. Tauber, J. R. Nechols \& J. J. Obrycki. 1983. Seasonal activity of parasitoids: control by external, internal and genetic factors, pp. 87-108. In V. K. Brown \& I. Hodek [eds.], Diapause and life cycle strategies in insects. Junk, The Hague.

Tauber, M. J., C. A. Tauber \& S. Masaki. 1985. Adaptations to hazardous seasonal conditions: dormancy, migration, and polyphenism, pp. 149-183. In C. B. Huffaker \& R. L. Rabb [eds.], Ecological entomology. Wiley, New York.

1986. Seasonal adaptations of insects. Oxford Univ., New York.

Worthley, H. N. 1923. The squash bug in Massachusetts. J. Econ. Entomol. 16: 73-79.

Received for publication 5 February 1987; accepted 21 December 1987. 